\title{
Vitamin D Levels, Body Composition, and Metabolic Factors in Asian Indians: Results from the Metabolic Syndrome and Atherosclerosis in South Asians Living in America Pilot Study
}

\author{
Janet M. Chiang ${ }^{a}$ Frank Z. Stanczyk ${ }^{b}$ Alka M. Kanaya ${ }^{c}$ \\ aDivision of Endocrinology, University of California, San Francisco, CA, USA; ${ }^{b}$ Division of Reproductive \\ Endocrinology, Keck School of Medicine, Los Angeles, CA, USA; 'Division of General Internal Medicine, \\ University of California, San Francisco, CA, USA
}

\section{Keywords}

25-OH Vitamin D · Body composition · Metabolism ·

Cardiovascular disease · Diabetes · Asian Indians

\begin{abstract}
Background/Aims: Asian Indians have a high prevalence of vitamin D deficiency and metabolic syndrome. Vitamin D deficiency is associated with an increased risk of cardiovascular disease and diabetes. Methods: We performed a cross-sectional study of 150 Asian Indians (50\% male) from the San Francisco Bay Area. We assessed the association between $25-\mathrm{OH}$ vitamin $\mathrm{D}$ (25-OHD) levels and vitamin D deficiency with body composition (anthropometric and radiographic measures) and metabolic outcomes. Results: In both men and women, the presence of vitamin D deficiency was associated with higher systolic $(p=0.004)$ and diastolic $(p=0.01)$ blood pressure, and fasting glucose $(p=0.01)$. Only in women, vitamin $D$ deficiency status was associated with higher body mass index (BMI), waist-to-hip ratio, visceral fat area, and hepatic fat content after adjusting for age, income, and
\end{abstract}

\section{KARGER}

(C) 2018 S. Karger AG, Basel

E-Mail karger@karger.com

www.karger.com/anm physical activity level. In women, 25-OHD was also associated with fasting glucose after adjusting for age, income, and physical activity and further adjusting for BMI and waist circumference $(\beta-2.1,95 \% \mathrm{Cl}-0.86$ to $-0.01, p=0.04)$. This association between vitamin $D$ deficiency and metabolic parameters was not significant in men. Conclusions: A lower level of 25-OHD and vitamin D deficiency were associated with higher levels of metabolic factors among Asian Indians. Our findings suggest that 25-OHD metabolism may differ by the distribution of adipose tissue and involve previously unexplored pathways accounting for the variability in the role of vitamin D in cardiovascular disease. $\quad 02018 \mathrm{~s}$. Karger AG, Basel

\section{Introduction}

A growing body of evidence suggests vitamin $\mathrm{D}$ deficiency is associated with increased risk for cardiovascular disease [1-3], insulin resistance, incidence of type 2 diabetes [4,5], and hypertension [6]. The prevalence 
of vitamin D deficiency in South Asian populations is high (up to 38-40\%) [7] possibly due to darker skin pigmentation and use of clothing that covers extensive areas of the skin [8]. Compared to other ethnic groups in the United States, South Asians also have a higher prevalence of diabetes, visceral adiposity, and fatty liver associated with a higher risk for type 2 diabetes [9].

Most of the larger studies exploring the association between vitamin $\mathrm{D}$ levels and cardiovascular or metabolic risk have been done using white or ethnically diverse populations. A recent study found that there were racial/ethnic differences in the association of vitamin D and cardiovascular events [10], and this may well be the case for diabetes and the metabolic syndrome as well.

We performed a cross-sectional pilot study of South Asians in the San Francisco Bay Area to investigate the association of 25-OHD with metabolic risk factors and body composition.

\section{Material and Methods}

We used data collected in a cross-sectional study of 150 Asian Indians recruited from a population-based sample in the San Francisco Bay area from August 2006 to October 2007 for the Metabolic Syndrome and Atherosclerosis in South Asians Living in America (MASALA) pilot study. The institutional review board at the site conducting the MASALA study approved the study protocol, and informed consent was obtained from all study subjects. The sampling methods have been described previously [9]. Briefly, participants who self-identified as Asian Indian between the ages of 45 and 84 years were eligible. We excluded those with a history of any cardiovascular disease, atrial fibrillation, stroke, cardiac surgery, life expectancy less than 5 years, and cognitive impairment. Participants living in a nursing home, who did not speak English or Hindi, or those with plans to move out of the study region were also excluded. The use of vitamin D supplements was not an exclusion criterion, as we were interested in the association of serum vitamin D level and metabolic risk, regardless of how the level was achieved.

Participants completed questionnaires with help from a trained research assistant. We measured sociodemographic information and health behaviors. Physical activity was measured using a modified questionnaire that has been validated in several ethnic minority groups [11]. Weight was measured on a digital scale. Waist circumference was measured with a Gullick II tape at site of maximum circumference midway between the lower ribs and the anterior superior iliac spine. Blood pressure was averaged from 2 seated measurements using an automatic monitor (Philips-Agilent V24C, Andover, MA, USA). The total lean and fat mass was measured using dual-energy $\mathrm{X}$-ray absorptiometry (Hologic Discovery-Wi, Waltham, MA, USA), and abdominal visceral and subcutaneous fat area was determined using computed to- mography (CT, Philips Medical Systems, Best, The Netherlands) measuring the fat content between L4 and L5 while the participant was in the supine position. Hepatic fat attenuation was also determined by CT after measuring the minimal, maximal, and mean attenuation of 2 liver sites and 1 spleen site. The liver to spleen attenuation ratio of $<1$ was used to define fatty liver [12-14]. Metabolic syndrome was defined as waist circumference of $\geq 80 \mathrm{~cm}$ for women and $\geq 90 \mathrm{~cm}$ for men, using modified ATPIII guidelines $[15,16]$.

\section{Lab Measurements}

Blood samples for metabolic profiles were obtained after a 12-h fast. Fasting plasma glucose was determined using the glucose oxidase method (YSI 2300, Yellow Sprints, OH, USA), and total cholesterol, triglycerides, and HDL were measured using enzymatic methods (Quest, San Jose, CA, USA). The LDL level was then calculated using the Friedewald formula.

Serum samples that were stored at $-80^{\circ} \mathrm{C}$ and previously unthawed were used to measure 25-OHD levels approximately 2 years after blood collection. 25-OHD was measured by use of a commercial iodinated radioimmunoassay (RIA) kit (DiaSorin, Stillwater, MN, USA) with a preceding extraction step using acetonitrile to remove potentially interfering metabolites, as described previously. The performance characteristics of the RIA show parallelism of serially diluted patient samples, interassay coefficients of variation ranging from $8.2-11.0 \%$, and an assay sensitivity of 1.5 $\mathrm{ng} / \mathrm{mL}$. Vitamin D deficiency was defined by a $25-\mathrm{OHD}$ level of $<20 \mathrm{ng} / \mathrm{mL}$ [17].

\section{Statistical Analysis}

We used analysis of variance or chi-squared tests as appropriate for univariate analysis. We performed sex-stratified analysis to assess the relationship between vitamin 25-OHD levels and the body composition variables. We determined collinear body composition variables using the Spearman correlation. We used sequential multivariate logistic regression models that adjusted for age, income, exercise, and body composition variables using a stepwise approach. All statistical analyses were performed using STATA (version 13, 2013, StataCorp, College Station, TX, USA).

\section{Results}

There were 150 participants in the MASALA pilot study cohort. The mean 25-OHD level in this cohort was $19.0 \pm 7.1 \mathrm{ng} / \mathrm{mL}$ (range $5-55.5 \mathrm{ng} / \mathrm{mL}$ ); approximately $55 \%$ of the participants had vitamin D deficiency; $13 \%$ of the cohort was using a vitamin D supplementation. In women, the mean 25 -OHD level was $21.2 \pm 7.7 \mathrm{ng} /$ $\mathrm{mL}$. The $73 \%$ of postmenopausal women in this cohort had a mean 25 -OHD level of $22.0 \pm 7.8$ compared to $19.3 \pm 7.3$ among premenopausal women $(p=0.64)$. In men, the mean 25-OHD level was $17.0 \pm 5.7 \mathrm{ng} / \mathrm{mL}$. Fifty-two percent of participants with vitamin D deficiency met criteria for metabolic syndrome. Vitamin D deficiency $(25-\mathrm{OHD}<20 \mathrm{ng} / \mathrm{mL})$ was significantly associ- 
Table 1. Baseline characteristics of MASALA study participants by Vitamin D deficiency status*

\begin{tabular}{|c|c|c|c|}
\hline Age, years, mean & $56 \pm 7$ & $59 \pm 9$ & 0.02 \\
\hline Gender, male & $50(62)$ & $23(35)$ & 0.002 \\
\hline Education $\geq$ Bachelor's Degree & $41(51)$ & $37(57)$ & 0.719 \\
\hline \multicolumn{4}{|l|}{ Annual family income } \\
\hline$\leq$ USD 40,000 & $12(15)$ & $10(15)$ & 0.03 \\
\hline USD 40,000- 74,999 & $21(26)$ & $5(8)$ & \\
\hline Metabolic syndrome & $42(52)$ & $23(35)$ & 0.047 \\
\hline \multicolumn{4}{|l|}{ Health-related behaviors } \\
\hline History of ever smoking & $15(18)$ & $9(14)$ & 0.73 \\
\hline Exercise, MET-min/week & $1,050(420-2,415)$ & $1,552(945-2,895)$ & 0.02 \\
\hline Season of 25-OHD measurement & & & 0.06 \\
\hline Spring & $16(53)$ & $14(47)$ & \\
\hline
\end{tabular}

* Data shown are $n(\%)$ or median (interquartile range).

ated with younger age, sex, and lower family income (Table 1).

In sex-stratified univariate analyses, vitamin D deficiency in women was associated with higher body mass index (BMI; $27.8 \pm 6.3$ vs. $24.9 \pm 3.7 \mathrm{~kg} / \mathrm{m}^{2}, p=0.02$ ), waist circumference $(98.9 \pm 16.6$ vs. $91.2 \pm 12.1 \mathrm{~cm}, p=$ $0.02)$, abdominal visceral fat area (124 \pm 49 vs. $102 \pm 46$ $\left.\mathrm{cm}^{2}, p=0.05\right)$, abdominal subcutaneous fat area (325 \pm 154 vs. $\left.260 \pm 89 \mathrm{~cm}^{2}, p=0.03\right)$, total fat $(29.3 \pm 10.4$ vs. $24.5 \pm 5.7 \mathrm{~kg}, p=0.01$ ), and lower hepatic fat attenuation as measured by liver to spleen attenuation ratio $(1.1 \pm 0.3$ vs. $1.3 \pm 0.2, p<0.001$; Fig. 1$)$. On the other hand, in men, vitamin $\mathrm{D}$ deficiency was not significantly associated with any body composition factors.

In women, vitamin $\mathrm{D}$ deficiency was also significantly associated with a higher fasting glucose $(97 \pm 17$ vs. $89 \pm$ $12 \mathrm{mg} / \mathrm{dL}, p=0.03$ ), and there was a trend toward association with higher triglyceride and lower HDL-cholesterol levels in women (Fig. 2). In men, there was a trend toward higher incidence of diabetes, higher LDL, and higher diastolic blood pressure (DBP), though this was not significant.

We further investigated the association between vitamin D deficiency and body composition variables in women, creating multivariate models that were adjusted for age, family income, and exercise (Table 2). Vitamin D deficiency remained associated with $\mathrm{BMI}(p=0.02)$, waist circumference $(p=0.03)$, abdominal visceral fat area $(p=$ $0.05)$, subcutaneous fat $(p=0.03)$, total fat $(p=0.02)$, and hepatic fat content $(p<0.01)$ after adjustment for covariates.

Among the entire sample, there was an inverse relationship between vitamin $\mathrm{D}$ levels and fasting glucose $(p=0.02)$, which differed by sex (Table 3$)$. The inverse relationship between vitamin D levels and fasting glucose was significant in women $(p=0.03)$ but not in men $(p=$ $0.99)$. In women, the relationship remained robust after adjusting for age, income, and exercise. In both men and women, there was also an inverse relationship between serum vitamin $\mathrm{D}$ level and systolic blood pressure (SBP; $p=0.02)$ and $\operatorname{DBP}(p=0.001)$.

Next, we did further sequential adjustments with each body composition variable to study its effect on the association of vitamin D levels with fasting glucose, SBP, and DBP. The inverse relationship between vitamin D levels and fasting glucose remained with adjustment for BMI ( $p=0.03)$; however, the inverse association was no longer significant after adjusting for waist circumference, abdominal visceral fat, or percent body fat. The inverse relationship between vitamin $D$ level with both SBP and DBP remained robust after fully adjusting for BMI, waist circumference, and abdominal visceral fat ( $p=0.04$ for both SBP and DBP; Table 3 ). This relationship was attenuated with further adjusting with percent fat. 


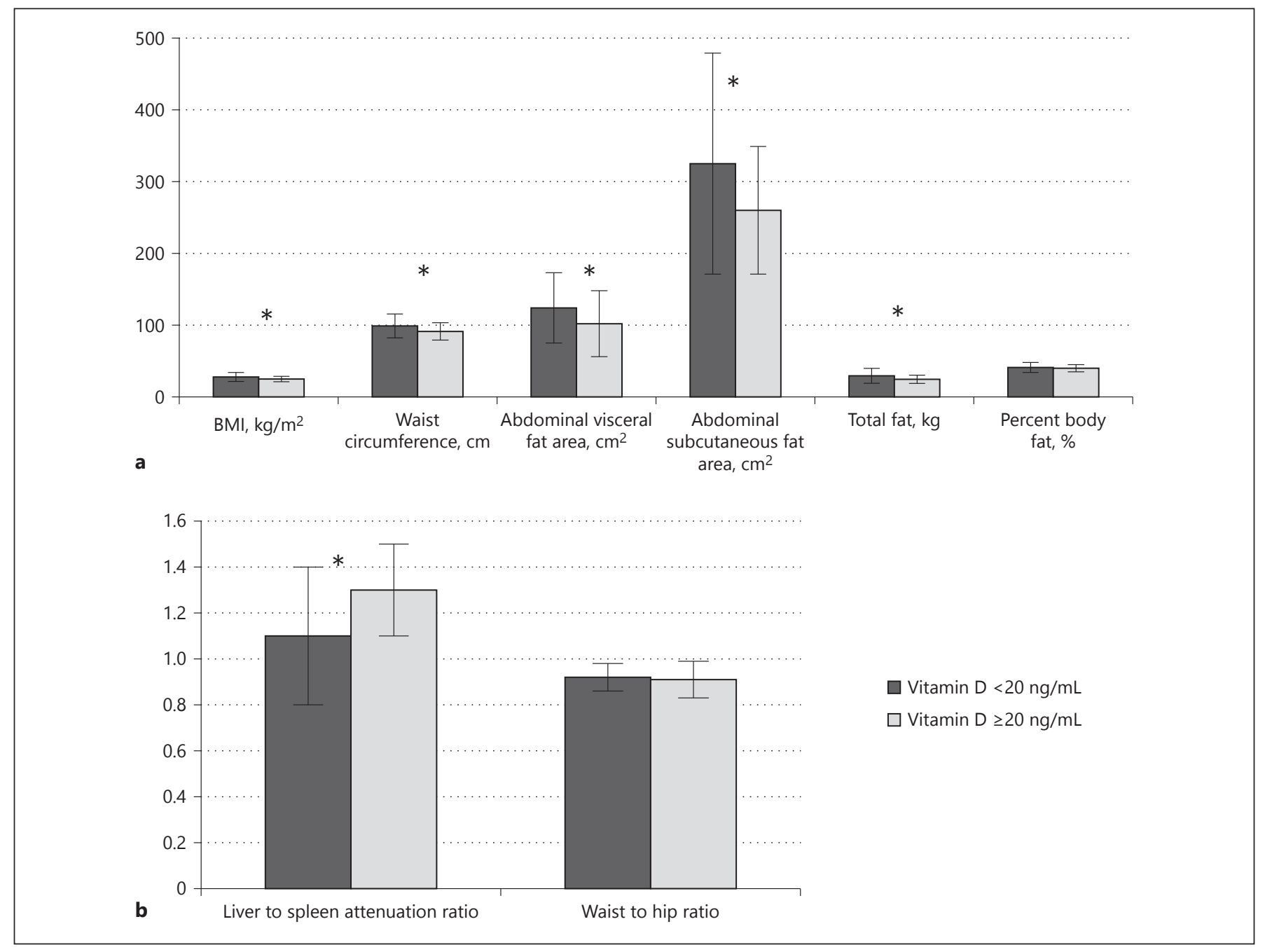

Fig. 1. a, b Vitamin D deficiency and body composition in women. ${ }^{*} p<0.05$.

\section{Discussion}

In this cross-sectional study, we found that higher 25OHD levels were significantly associated with lower blood pressure in Asian Indian men and women, and with lower fasting blood glucose. Lower 25-OHD levels were significantly associated with worse body composition measures such as higher BMI, visceral fat area, subcutaneous fat area, and hepatic fat attenuation in women alone. Furthermore, in women, 25-OHD levels were inversely associated with fasting glucose after adjusting for demographic factors, BMI and waist circumference, but was attenuated after addition of visceral or percent fat.

Few studies have looked at the relationship between 25-OHD and body composition. Young et al. [18] also described an inverse relationship between levels of 25-
OHD and 1,25-(OH)2D and abdominal and visceral adiposity in Hispanics and African Americans. Though our results largely agree with Young et al. [18], using a different ethnic subgroup, another important difference in our study was that we sex-stratified our data for body composition, given important differences in adiposity and fat distribution in women. To our knowledge, this is the first study looking at sex-stratified data for the relationship between vitamin D levels and body composition or metabolic risk factors.

The finding that only among women was low 25OHD associated with body composition suggests that a possible sex-specific pathway that may not have yet been elucidated, possibly through the vitamin $\mathrm{D}$ binding protein. Jiang et al. [19] have demonstrated that there are polymorphisms found in the vitamin D-binding protein, 


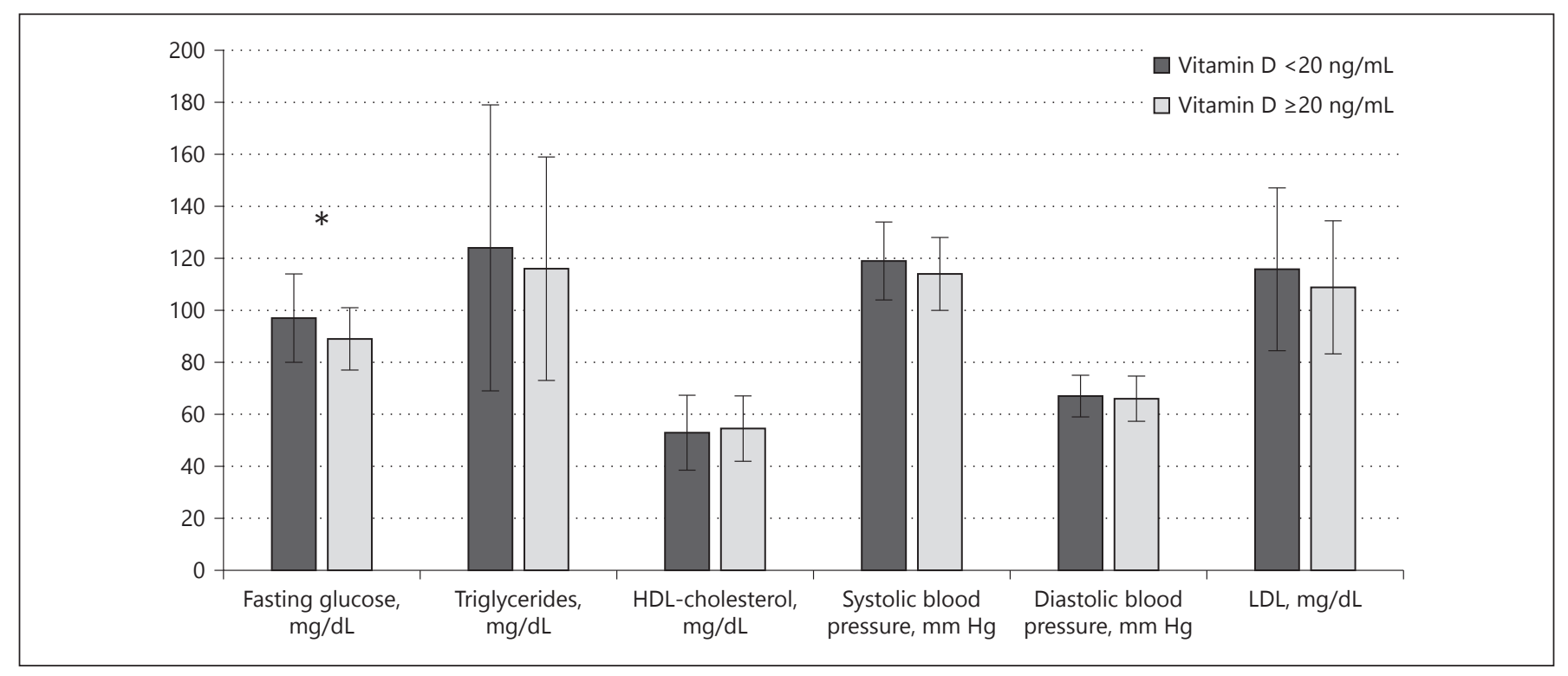

Fig. 2. Vitamin D and metabolic factors in women. ${ }^{*} p<0.05$.

Table 2. Association between vitamin D deficiency and body composition measures in women

\begin{tabular}{|c|c|c|c|c|c|c|}
\hline $\begin{array}{l}\text { Body } \\
\text { composition }\end{array}$ & \multicolumn{3}{|c|}{ Unadjusted } & \multicolumn{3}{|c|}{ Adjusted* } \\
\hline Hip circumference, $\mathrm{cm}$ & 2.43 & (1.16 to 11.8$)$ & 0.02 & 2.36 & (1.01 to 12.2$)$ & 0.02 \\
\hline Waist circumference, $\mathrm{cm}$ & 2.24 & $(0.84$ to 14.3$)$ & 0.03 & 2.28 & (0.985 to 14.9$)$ & 0.03 \\
\hline Visceral fat area, $\mathrm{cm}^{2}$ & 1.99 & $(-0.06$ to 44.6$)$ & 0.05 & 2.06 & $(0.76$ to 47.3$)$ & 0.04 \\
\hline Liver:spleen ratio (hepatic fat content) & -3.61 & $(-0.34$ to -0.10$)$ & $<0.01$ & -3.22 & $(-0.32$ to -0.08$)$ & $<0.01$ \\
\hline
\end{tabular}

* Adjusted for age, family income, and exercise. Std $\beta$, standard $\beta$.

which may be contributing to obesity, and these were more significantly associated in women. Future studies may be warranted to look at vitamin D-binding protein levels in men and women and whether this mediates the effect between 25-OHD and body composition. It would also be interesting to measure "free" 25-OHD levels and see if the associations with body composition and metabolic risk similarly differ on the basis of sex. Another hypothesis to consider would be to check if there is an interaction between estrogen and vitamin $\mathrm{D}$ level. However, in our cohort, there was not a significant difference in the 25-OHD levels between premenopausal and postmenopausal women. Furthermore, we did not find an interaction between 25-OHD deficiency status and menopausal status on the association between metabolic factors.

We found that 25-OHD deficiency is also significantly associated with worse cardiovascular and metabolic factors, such as higher fasting plasma glucose and blood pressure, which remained robust after adjusting for age, family income, and exercise level. This result agrees with multiple previous retrospective studies also showing similar results $[1-5,8,18,20]$. We further examined whether the relationship between 25-OHD and fasting glucose, SBP, and DBP was mediated by body composition. The association between 25-OHD and fasting glucose remained after adjusting for BMI, though it was attenuated with further adjusting with other body composition vari- 


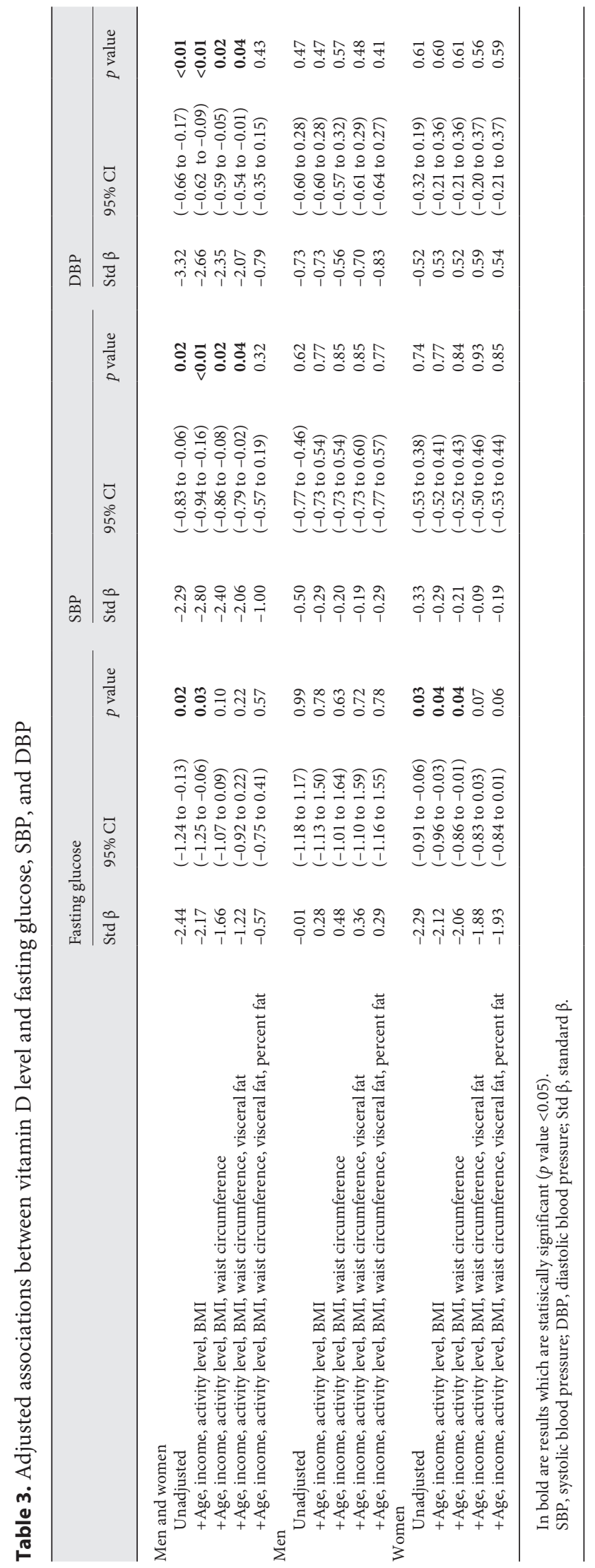

ables. The relationship between SBP, DBP, and 25-OHD remained after adjusting for BMI, waist circumference, and visceral fat. This suggests that the relationship between 25-OHD and fasting glucose, SBP, and DBP is not completely explained by adiposity, but perhaps by other mechanisms. A previous study by Sulistyoningrum et al. [20] also investigated whether the association of 25-OHD and blood pressure is mediated by adiposity. Our results are consistent in that the relationship between 25-OHD and blood pressure was independent of adiposity. Future studies with larger sample sizes would provide further interesting insight into the role of adiposity in 25-OHD and metabolic risk factors.

Randomized interventional trials of vitamin D supplementation have so far not shown to result in improved metabolic or cardiovascular risk factors [21, 22]. However, it is important to note that all of these studies have been conducted in mixed ethnic cohorts. Increasing data regarding the ethnic differences in these correlations are now available $[10,23]$. More data suggests that vitamin D may play a difference in racial differences in blood pressure. Various reasons may contribute to racial differences in the correlation between vitamin D and metabolic risk. One attractive hypothesis would be that racial differences in vitamin D-binding protein levels contribute to differences in metabolic risk factors [24].

The strength of this study includes using sex-stratified analyses to examine the relationship between 25OHD deficiency and body composition, which only a few studies have done in the past. This is also the first study to look specifically at the vitamin D status and metabolic factors in South Asians. There are also several limitations that need to be acknowledged. Our study design was cross-sectional and therefore, a causal relationship between vitamin $\mathrm{D}$ and metabolic factors and body composition could not be established. The relatively small sample size also raises the question of lack of power to detect smaller associations between 25$\mathrm{OHD}$ and body composition, and other metabolic variables such as leptin, adiponectin, insulin levels, lipid levels, especially in the sex-stratified data. Finally, we acknowledge that there is some inherent systematic bias introduced by the RIA assay used for measuring 25OHD compared to LC-MS measurements. However, the correlation between the 2 methods of measurement is quite high (0.97) [25] and therefore, should have minimal effect on our reported results.

In this study, we have shown that 25-OHD deficiency is significantly associated with worse metabolic outcomes including higher blood pressure and fasting glucose. It is 
also associated with a worse body composition profile in women. Future studies may involve obtaining quantitative measures of the vitamin D-binding protein and "free" $25-\mathrm{OHD}$ in our cohort. Furthermore, it would be interesting to compare levels of vitamin D-binding protein in men versus women in our cohort as well as levels in South Asians versus levels reported for other ethnic groups. A next step would also be to see if there is a similar association between vitamin D-binding protein and metabolic outcomes.

\section{Acknowledgments}

The MASALA study was supported by the National Institutes of Health (grant no. K23 HL080026-01) and by NIH/NCRR UCSF-CTSI Grant Number UL1 RR024131.

\section{Disclosure Statement}

The authors declare that they have no conflicts of interest to disclose.

\section{References}

1 Wang TJ, Pencina MJ, Booth SL, Jacques PF, Ingelsson $\mathrm{E}$, Lanier $\mathrm{K}$, Benjamin $\mathrm{EJ}$, D'Agostino RB, Wolf M, Vasan RS: Vitamin $\mathrm{D}$ deficiency and risk of cardiovascular disease. Circulation 2008;117:503-511.

2 Maki KC, Fulgoni VL 3rd, Keast DR, Rains TM, Park KM, Rubin MR: Vitamin D intake and status are associated with lower prevalence of metabolic syndrome in U.S. adults: National Health and Nutrition Examination Surveys 2003-2006. Metab Syndr Relat Disord 2012;10:363-372.

3 Vacek JL, Vanga SR, Good M, Lai SM, Lakkireddy D, Howard PA: Vitamin D deficiency and supplementation and relation to cardiovascular health. Am J Cardiol 2012;109:359363.

4 Kayaniyil S, Vieth R, Retnakaran R, Knight JA, Qi Y, Gerstein HC, Perkins BA, Harris SB, Zinman B, Hanley AJ: Association of vitamin $\mathrm{D}$ with insulin resistance and beta-cell dysfunction in subjects at risk for type 2 diabetes. Diabetes Care 2010;33:1379-1381.

5 Song Y, Wang L, Pittas AG, Del Gobbo LC, Zhang C, Manson JE, Hu FB: Blood 25-hydroxy vitamin D levels and incident type 2 diabetes: a meta-analysis of prospective studies. Diabetes Care 2013;36:14221428.

6 Vimaleswaran KS, Cavadino A, Berry DJ; LifeLines Cohort Study investigators, Jorde R, Dieffenbach AK, Lu C, Alves AC, Heerspink HJ, Tikkanen E, Eriksson J, Wong A, Mangino M, Jablonski KA, Nolte IM, Houston DK, Ahluwalia TS, van der Most PJ, Pasko D, Zgaga L, Thiering E, Vitart V, Fraser RM, Huffman JE, de Boer RA, Schottker B, Saum KU, McCarthy MI, Dupuis J, Herzig $\mathrm{KH}$, Sebert S, Pouta A, Laitinen J, Kleber ME, Navis G, Lorentzon M, Jameson K, Arden N, Cooper JA, Acharya J, Hardy R, Raitakari O, Ripatti S, Billings LK, Lahti J, Osmond C, Penninx BW, Rejnmark L, Lohman KK, Paternoster L, Stolk RP, Hernandez DG, Byberg L, Hagstrom E, Melhus H, Ingelsson E, Mellstrom D, Ljunggren O, Tzoulaki I, McLachlan S, Theodoratou E, Tiesler CM, Jula A, Na- varro P, Wright AF, Polasek O; International Consortium for Blood Pressure (ICBP); Cohorts for Heart and Aging Research in Genomic Epidemiology (CHARGE) consortium; Global Blood Pressure Genetics (Global BPGen) consortium; Caroline Hayward, Wilson JF, Rudan I, Salomaa V, Heinrich J, Campbell H, Price JF, Karlsson M, Lind L, Michaelsson K, Bandinelli S, Frayling TM, Hartman CA, Sorensen TI, Kritchevsky SB, Langdahl BL, Eriksson JG, Florez JC, Spector TD, Lehtimaki T, Kuh D, Humphries SE, Cooper C, Ohlsson C, Marz W, de Borst MH, Kumari M, Kivimaki M, Wang TJ, Power C, Brenner H, Grimnes G, van der Harst P, Snieder H, Hingorani AD, Pilz S, Whittaker JC, Jarvelin MR, Hypponen E: Association of vitamin D status with arterial blood pressure and hypertension risk: a mendelian randomisation study. Lancet Diabetes Endocrinol 2014;2:719-729.

7 Mithal A, Wahl DA, Bonjour JP, Burckhardt P, Dawson-Hughes B, Eisman JA, El-Hajj Fuleihan G, Josse RG, Lips P, Morales-Torres J: Global vitamin D status and determinants of hypovitaminosis D. Osteoporos Int 2009;20: 1807-1820.

8 Whitelaw DC, Scally AJ, Tuffnell DJ, Davies TJ, Fraser WD, Bhopal RS, Wright J, Lawlor DA: Associations of circulating calcium and 25-hydroxyvitamin D with glucose metabolism in pregnancy: a cross-sectional study in European and South Asian women. J Clin Endocrinol Metab 2014;99:938-946.

9 Kanaya AM, Wassel CL, Mathur D, Stewart A, Herrington D, Budoff MJ, Ranpura V, Liu K: Prevalence and correlates of diabetes in South asian indians in the United States: findings from the metabolic syndrome and atherosclerosis in South Asians living in America study and the multi-ethnic study of atherosclerosis. Metab Syndr Relat Disord 2010;8: 157-164.

10 Robinson-Cohen C, Hoofnagle AN, Ix JH, Sachs MC, Tracy RP, Siscovick DS, Kestenbaum BR, de Boer IH: Racial differences in the association of serum 25-hydroxyvitamin D concentration with coronary heart disease events. JAMA 2013;310:179-188.

11 Ainsworth BE, Irwin ML, Addy CL, Whitt MC, Stolarczyk LM: Moderate physical activity patterns of minority women: the crosscultural activity participation study. J Womens Health Gend Based Med 1999;8:805813

12 Jacobs JE, Birnbaum BA, Shapiro MA, Langlotz CP, Slosman F, Rubesin SE, Horii SC: Diagnostic criteria for fatty infiltration of the liver on contrast-enhanced helical CT. AJR Am J Roentgenol 1998;171:659664

13 Ricci C, Longo R, Gioulis E, Bosco M, Pollesello P, Masutti F, Croce LS, Paoletti S, de Bernard B, Tiribelli C, Dalla Palma L: Noninvasive in vivo quantitative assessment of fat content in human liver. J Hepatol 1997;27: 108-113.

14 Piekarski J, Goldberg HI, Royal SA, Axel L, Moss AA: Difference between liver and spleen CT numbers in the normal adult: its usefulness in predicting the presence of diffuse liver disease. Radiology 1980;137:727-729.

15 Grundy SM, Cleeman JI, Daniels SR, Donato KA, Eckel RH, Franklin BA, Gordon DJ, Krauss RM, Savage PJ, Smith SC Jr, Spertus JA, Costa F: Diagnosis and management of the metabolic syndrome: an American Heart Association/National Heart, Lung, and Blood Institute Scientific Statement. Circulation 2005; 112:2735-2752

16 Ramachandran A, Snehalatha C, Satyavani K, Sivasankari S, Vijay V: Metabolic syndrome in urban Asian Indian adults - a population study using modified ATP III criteria. Diabetes Res Clin Pract 2003;60:199204.

17 Holick MF: Vitamin D deficiency. N Engl J Med 2007;357:266-281.

18 Young KA, Engelman CD, Langefeld CD, Hairston KG, Haffner SM, Bryer-Ash M, Norris JM: Association of plasma vitamin D levels with adiposity in Hispanic and African Americans. J Clin Endocrinol Metab 2009;94: 3306-3313. 
19 Jiang H, Xiong DH, Guo YF, Shen H, Xiao P, Yang F, Chen Y, Zhang F, Recker RR, Deng HW: Association analysis of vitamin D-binding protein gene polymorphisms with variations of obesity-related traits in Caucasian nuclear families. Int J Obes (Lond) 2007;31: 1319-1324.

20 Sulistyoningrum DC, Gasevic D, Green TJ, Lear SA, Devlin AM: Adiposity and the relationship between vitamin $\mathrm{D}$ and blood pressure. Metabolism 2013;62:17951802.

21 Seida JC, Mitri J, Colmers IN, Majumdar SR, Davidson MB, Edwards AL, Hanley DA, Pittas
AG, Tjosvold L, Johnson JA: Clinical review: Effect of vitamin D3 supplementation on improving glucose homeostasis and preventing diabetes: a systematic review and meta-analysis. J Clin Endocrinol Metab 2014;99:3551-3560.

22 Salekzamani S, Mehralizadeh H, Ghezel A, Salekzamani Y, Jafarabadi MA, Bavil AS, Gargari BP: Effect of high-dose vitamin D supplementation on cardiometabolic risk factors in subjects with metabolic syndrome: a randomized controlled double-blind clinical trial. J Endocrinol Invest 2016;39:1303-1313.

23 Fiscella K, Winters P, Tancredi D, Franks P: Racial disparity in blood pressure: is vitamin $\mathrm{D}$ a factor? J Gen Intern Med 2011;26:11051111.

24 Powe CE, Evans MK, Wenger J, Zonderman AB, Berg AH, Nalls M, Tamez H, Zhang D, Bhan I, Karumanchi SA, Powe NR, Thadhani R: Vitamin D-binding protein and vitamin D status of black Americans and white Americans. N Engl J Med 2013;369:1991-2000.

25 Roth HJ, Schmidt-Gayk H, Weber H, Niederau C: Accuracy and clinical implications of seven 25-hydroxyvitamin D methods compared with liquid chromatography-tandem mass spectrometry as a reference. Ann Clin Biochem 2008;45:153-159. 